\title{
Campos de intervenções organizacionais: a contribuição das ciências humanas para uma leitura crítica das propostas de gestão das organizações de saúde
}

\author{
Auristela Maciel Lins ${ }^{1}$ \\ Luiz Carlos de Oliveira Cecílio ${ }^{2}$
}

LINS, A.M.; CECÍLIO, L.C.O. Organizational intervention fields: the contribution of Humanities to a critical view of the proposals on health organizations management. Interface - Comunic., Saúde, Educ., v.11, n.23, p.503-14, set/dez 2007.

This article aims at presenting an analytical frame to be used by organization researchers, health managers, and health evaluators as a guide to promote critical analysis of organizational interventions usually presented as powerful management tools for changing undesirable situations. The current analytical scheme stems from a research on doctoral theses submitted from 2000 through 2004 in major Brazilian universities. It was intended to identify the main paradigms used in such recent academic work. It comprises "ideal types" known as "organizational intervention fields" based on some theoretical productions in the area of Human Sciences.

KEY WORDS: Organizational analysis. Health systems. Health management. Health evaluation.

O objetivo deste artigo é apresentar um esquema analítico que possa ser utilizado por estudiosos das organizações, sobretudo gestores e avaliadores em saúde, como roteiro para a leitura crítica de propostas de intervenção organizacional que lhes são apresentadas no cotidiano de suas organizações e que se pretendem transformadoras de uma situação indesejada. O esquema ora apresentado resulta de uma pesquisa que discutiu teses de doutorado defendidas entre 2000 e 2004, nas principais universidades brasileiras, procurando identificar os paradigmas utilizados nessas obras acadêmicas recentes. Compõe-se de tipos ideais denominados "campos de intervenções organizacionais", construídos com a contribuição de algumas produções teóricas das ciências humanas.

PALAVRAS-CHAVE: Análise organizacional. Sistemas de saúde. Gestão em saúde. Avaliação em saúde.

\footnotetext{
${ }^{1}$ Médica; doutora em Saúde Coletiva; especialista em regulação e vigilância sanitária, Agência Nacional de Vigilância Sanitária (ANVISA); docente voluntária, Departamento de Saúde Coletiva, Faculdade de Saúde, Universidade de Brasília. Brasília, DF. <auristela@unb.br>

${ }^{2}$ Médico; doutor em Saúde Coletiva; departamento de Medicina Preventiva, Escola Paulista de Medicina, Universidade Federal de São Paulo. São Paulo, SP. <cecilioluiz@uol.com.br>
} 


\section{Introdução}

A produção teórica brasileira na área da gestão e avaliação em saúde tem sido crescente nos últimos anos, notadamente nos que sucederam à Constituição de 1988 e à criação do Sistema único de Saúde - SUS. Ela toma corpo após a institucionalização, ou seja, a inscrição, nos marcos legais nacionais, do sistema de saúde buscado pelo Movimento Sanitário. O mesmo se dá com a avaliação em saúde, que surgiu com a necessidade de estudos operacionais que produzissem conhecimento sobre os estabelecimentos, a gerência, a produção e o impacto dos serviços, conhecimentos esses que pudessem fornecer subsídios ao aperfeiçoamento do sus.

Pesquisadores inseridos em renomados centros acadêmicos da área da saúde têm apresentado uma importante produção teórica no campo da gestão $e$ avaliação em saúde nos últimos anos. Uma revisão bibliográfica de teses defendidas entre 1995 e 2004, promovida por Lins (2004), encontrou um incremento da produção teórica de $175 \%$ para a gestão e de $130 \%$ para a avaliação.

A literatura da área mostra-se, também, muito rica, como se pode notar pela crescente publicação de livros, artigos em revistas do campo da Saúde Coletiva $e$ comunicação de trabalhos de intervenção em organizações da saúde, focando ora a gestão, ora a avaliação, ou mostrando seu forte imbricamento.

É possível afirmar que toda essa produção sobre gestão e avaliação é influenciada pelas múltiplas correntes teóricas das ciências humanas, em particular da Sociologia, que disputam espaço no pensamento contemporâneo, na medida em que nessa área de conhecimento não há um paradigma hegemônico, no sentido definido por Kuhn (1975). Tal paradigma, aceito como consensual, é que permitiria o desenvolvimento de uma "ciência normal", qual seja, a condução do conjunto de investigações de uma determinada área de saber referenciado ao mesmo paradigma considerado como válido por determinada comunidade acadêmica. Do ponto de vista do presente artigo, é interessante destacar que, por sua vez, essas várias formas de se pensar o mundo social, em disputa entre si, além de influenciarem o recorte dos estudos acadêmicos, acabam influenciando, de forma mais ou menos direta, os tomadores de decisões - ou o grupo que delas participa - em organizações sociais como as da saúde (Curado, 2007; Souza, 2001).

Gestores e avaliadores em saúde, em particular quando optam por estratégias de condução de mudanças organizacionais, são direta ou indiretamente influenciados por diferentes maneiras de interpretar a realidade e de promover sua produção (ou reprodução), enfim, pelas disputas de idéias presentes nos espaços sociais, tenham ou não consciência delas.

$\mathrm{Na}$ acepção fenomenológica de crença, acreditamos que grande parte das escolhas dos dirigentes acontece sem o conhecimento dos fundamentos teóricos e metodológicos da intervenção proposta para a organização que dirigem. Assim, o gestor e o avaliador não sabem como a proposta metodológica apresentada se acerca da realidade e como se sugere que ela seja tratada - a ser transformada ou mantida.

Este artigo tem por objetivo apresentar um esquema analítico que possa ser utilizado por pesquisadores e estudiosos da área de gestão e avaliação de serviços de saúde, por estudiosos da teoria das organizações, sobretudo por gestores e avaliadores das organizações de saúde, como uma espécie de 'roteiro' para uma 
leitura crítica tanto da produção teórica da área, quanto de propostas concretas de intervenção organizacional.

\section{Um breve resgate da influência de algumas produções das ciências humanas na gestão $e$ avaliação em saúde}

O ponto de partida de nossa reflexão é considerar que uma leitura dos trabalhos sobre gestão e avaliação das organizações de saúde revela, de uma forma bastante constante, um forte aprisionamento, por parte dos autores, ao referencial estrutural-funcionalista, no caso da gestão, e a um referencial sistemicista, no caso da avaliação.

Parsons é o autor que, em nossa opinião, consegue expressar a síntese do que estamos denominando, neste trabalho, de estrutural-funcionalismo, ao tentar construir uma teoria universal para explicar a dinâmica social (Quintaneiro \& Oliveira, 2002; Domingues, 2001a, 2001b). O estrutural-funcionalismo de Talcott Parsons pode ser caracterizado pelos seguintes aspectos: i) a ausência formal de conflitos de interesse entre os sujeitos, uma vez que os interesses "da sociedade" são introjetados pelos indivíduos, levando-os a buscar a integração social. É um mundo onde não há conflitos ou disputas por interesses ou projetos; ii) essa introjeção das normas justifica a busca pelo consenso e a concepção da organização/sociedade como sistema que tende à homeostase; iii) as divergências são caracterizadas como disfunções a serem incorporadas pelo sistema, o que justifica a concepção da regularidade social, e iv) a presença da disciplina e do controle como eixo central dos métodos de gestão, aderindo, assim, à racionalidade gerencial hegemônica.

Parsons influenciou toda a produção sociológica americana, inglesa, alemã $e$, também, brasileira. Nos Estados Unidos, manteve compromissos expressos com o stabilishment e, de forma geral, com o ideário liberal (Domingues, 2001b). Sua concepção das organizações como sociedades em miniatura influenciou os profissionais ditos institucionalistas, que possuíam uma prática de intervenção nas organizações no sentido de melhorar o seu desempenho (Silverman, 1975).

Em conjunto com a teoria clássica da administração de Taylor e Fayol, o estrutural-funcionalismo de Parsons influenciou toda uma gama de produções teóricas e intervenções práticas no campo da gestão e avaliação. Na área de avaliação em saúde, a produção teórica e os relatos de experiências mostram-se fortemente referenciados em Avedis Donabedian, que possui uma extensa produção teórica, em especial, sobre a organização da atenção médica e sobre sua avaliação. A proposta de avaliação dos serviços de saúde de Donabedian baseia-se no tripé metodológico: estrutura, processo e resultado (Donabedian, 1988, 1985, 1982). Esse tripé é uma clássica representação da concepção sistemicista de organização ou uma aplicação prática da teoria de sistemas ao estudo das organizações de saúde. Embora a proposta focalize a atenção médica, sua obra tem influenciado avaliadores dos mais diversos aspectos da instituição saúde.

Os estudiosos das organizações vinculados à teoria de sistemas, ao criticar a concepção clássica de organização como um modelo mecânico, propõem, como modelo alternativo, o orgânico. Assim, as organizações passaram a ser comparadas ao corpo humano, buscando sempre o equilíbrio ou a homeostase (Silverman, 1975). Embora a representação seja diferente, o paradigma se mantém 
funcionalista: não há espaço para conflitos de interesse. O exemplo mais clássico dessa concepção pode ser dado pela avaliação do pólo "resultado". Os resultados que se buscam medir são os "da organização", sem considerar a existência de diferentes sujeitos com objetivos diversos em uma mesma organização. Parte-se, portanto, do princípio que os valores ou orientações dentro de uma organização passam a ser compartilhados por todos os indivíduos, pela introjeção dos valores culturais do grupo - tese defendida por Parsons.

Ainda no campo da avaliação, alguns outros autores, muito utilizados por ampla maioria dos avaliadores, são Cohen \& Franco (1994) e Aguilar \& Ander-Egg (1995). É interessante notar que, apesar de estas duas duplas de autores não referenciarem Donabedian nas bibliografias de suas obras, têm muito em comum com ele.

Aguilar \& Ander-Egg (1995) permanecem presos a uma dicotomia funcionalista ao atribuírem racionalidades próprias ao desempenho de papéis específicos na sociedade ou nas organizações: a racionalidade política é dos políticos, a racionalidade técnica é dos técnicos. Os autores também não valorizam uma possível co-gestão de um processo avaliativo (Campos, 2000, 1977), que pudesse criar espaço para a negociação dos diferentes projetos envolvidos, quando criticam a proposta de avaliação participativa de Patton (1982), afirmando que

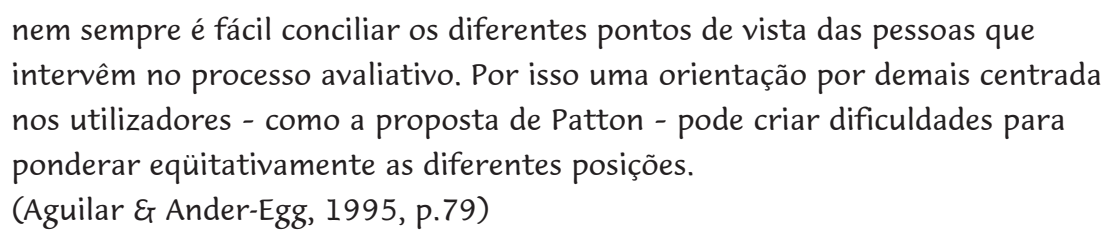

Queremos reiterar, citando esses autores, o que já explicitamos um pouco antes, qual seja, que freqüentemente introjetamos e utilizamos metodologias propostas por teóricos ou por profissionais que atuam como consultores de forma acrítica, ou mesmo sem compreender as concepções teóricas nas quais se baseiam. Esses autores adotam uma forma de ver a realidade criticada, por sua excessiva simplificação, por estudiosos filiados a linhas de pensamento que se contrapõem, de forma mais ou menos radical, ao positivismo sociológico.

Em contraposição ao paradigma estrutural-funcionalista, há todo um esforço de construção de novas formas de se pensar a vida organizacional. Como exemplo, podemos indicar o conjunto de textos reunidos na coletânea organizada por Stewart Clegg et al. e editada, no Brasil, pela Atlas, em inúmeras reimpressões desde 1991, com o título de "Handbook de estudos organizacionais", comentada por autores brasileiros. Na nossa investigação, optamos por buscar algumas contribuições teóricas provenientes do campo das Ciências Humanas, fazendo uma bricolagem intencional de abordagens teóricas bastante distintas, como: a teoria da ação baseada nos trabalhos de Schutz, o debate contemporâneo em torno da relação "estrutura"/ação, trazido por Giddens e Bourdieu e, finalmente, as contribuições da socioanálise francesa, em particular os trabalhos de Lourau e Lapassade, para uma reflexão mais ampliada dos conceitos de instituição/institucionalização e, em decorrência, uma conceituação mais elaborada de organização. 
A teoria da ação, com forte contribuição para se pensar a gestão, tem sido desenvolvida em trabalhos que se filiam à sociologia fenomenológica, cujos expoentes são Schultz (1979) e Berger \& Luckmann (1994). Esses autores desenvolveram efetivos esforços na tentativa de construir instrumentos metodológicos para compreender a dinâmica social considerando a filosofia fenomenológica, como a concebiam Husserl e Bergson, e a sociologia compreensiva, como a formulou Max Weber. Contrapondo-se ao objetivismo positivista que interpreta os fenômenos sociais como 'coisas' que se podem medir e comparar, os fenomenologistas sociais introduzem, no estudo da dinâmica social, a perspectiva subjetiva. Argumentam que a vida cotidiana se apresenta ao indivíduo como um mundo intersubjetivo, no qual participam outros homens que têm 'estoques de conhecimento' e 'histórias biográficas' diferentes, portanto, perspectivas $e$ interpretações diferentes do mundo. Assim, os fenômenos sociais não se podem medir e comparar.

Nesse sentido, em sua forma mais radical, a expressão metodológica dessa linha de pensamento pressupõe o estudo dos atores ou pequenos grupos situados biograficamente, o estudo dos estoques de conhecimento com os quais interpretam e dos significados que atribuem ao fenômeno para sua melhor compreensão (Boudon, 1995). Segundo Minayo (1993), para a Fenomenologia, os pequenos grupos são os responsáveis pela identidade dos indivíduos, sua estabilidade e seu sistema de significados, na medida em que partilham uma mesma visão de mundo.

Teóricos organizacionais vinculados a essa linha de pensamento propõem $o$ enfoque da teoria da ação para a análise das organizações. Um bom exemplo contemporâneo é Erhard Friedberg $(1995,1993)$. Estes atores contrapõem-se diretamente à concepção positivista de organização, que vê os fatos sociais como imposições ao homem, atribuindo-lhes respostas modelares no processo de interação social. Ao definirem as organizações como produções dos indivíduos que nelas interagem e como reflexo das estruturas e significados prevalentes na sociedade em cada momento histórico, contribuem no sentido de se construírem alternativas para se pensar a vida nas organizações de uma perspectiva mais filiada a uma sociologia da ação, cuja ênfase é, em última instância, sobre uma irredutível margem de manobra, liberdade e criatividade na ação humana (Boudon, 1995).

O estruturismo ou estruturacionismo se constitui em outra linha de pensamento no campo das ciências humanas que se propõe explicar a dinâmica social tentando romper com a dicotomia instalada nas discussões sociológicas entre objetivismo e subjetivismo ou entre estrutura e ação. Giddens (1978), um dos seus principais expoentes, defende o conceito de Dualidade da Estrutura, afirmando que "as estruturas sociais são tanto constituídas pela ação humana, como também, ao mesmo tempo, são o próprio meio desta constituição" (p.129).

Assim, rejeita o princípio da uniformidade - que professa a existência de uma ordem trans-histórica de forças ou relações entre entidades - defendido pelos autores da linha positivista, mas reconhece as regularidades sociais contrapondo-se às teorias subjetivistas - para as quais a sociologia deveria se ater à investigação das condutas situadas, por serem únicas e particulares de qualquer objeto de investigação, expressas, sobretudo, pelo interacionismo simbólico (Cohen, 1999).

Outro importante autor do estruturismo é Pierre Bourdieu que, em suas produções teóricas, retoma a polêmica entre subjetivismo e objetivismo. Bourdieu critica a fenomenologia e o estruturalismo, negando a perspectiva deste último, 
que apresenta o ator social como mero executor de normas e regras. Por outro lado, contrapõe-se à primeira, que rejeita o conhecimento objetivo.

Bourdieu retoma, da escolástica, a idéia de hábito, ou disposição estável para se operar em determinada direção (Ortiz, 1983), e propõe seu conceito de habitus como "um sistema de disposições duráveis, estruturas estruturadas predispostas a funcionarem como estruturas estruturantes" (Bourdieu, 1983, p.61). Ao locus onde as posições dos agentes encontram-se a priori fixadas, onde ocorrem as disputas por interesses específicos, Bourdieu dá o nome de "campo". O campo é o espaço onde se manifestam relações de poder, estruturado com base na distribuição desigual do "capital social" dos agentes (Ortiz,1983).

Em ambos os conceitos, o autor tenta ir além da discussão sobre objetivismo e subjetivismo, onde estão presentes ação e estrutura em uma relação dialética. Certamente, de forma proposital, não há uma explícita contraposição entre estrutura e ação na obra deste autor, talvez para caracterizar a dinâmica da realidade social, onde não ocorre uma dicotomia tão clara. O habitus responde pelo pólo da ação, mas também pela memória social, enquanto o "campo", que abriga as disputas, é também o condicionante dessas disputas pela desigual distribuição de capital social entre os agentes/grupos.

Uma outra contribuição importante para a leitura crítica do estrutural funcionalismo vem do chamado movimento institucionalista, surgido na década de 1960 na França, ao contestar as concepções positivistas, estruturalistas e subjetivistas da sociedade, aportando novas e potentes contribuições teóricas para a crítica ao paradigma estrutural-funcionalista das organizações. Esse movimento se constitui por diversas tendências, sendo as mais conhecidas a esquizoanálise, que tem em Gilles Deleuze e Felix Guattari seus mais criativos pensadores, e a Análise Institucional ou Socianálise, cujos autores mais conhecidos no Brasil são George Lapassade e René Lourau.

É, sobretudo, mediante a refutação do conceito de 'instituição', conforme expressado pelas linhas de pensamento precedentes, que os autores da socioanálise propõem uma terceira via de análise da sociedade. Os analistas institucionais consideram importante para a compreensão da dinâmica social as diferenças conceituais entre instituição e organização.

Em contraposição ao conceito de instituição, conforme professado pelos positivistas, como fato, ou algo preestabelecido, enfim, como uma herança de padrões culturais transmitidos pela educação, Lapassade \& Lourau (1972) conceituam instituição como a forma assumida pela reprodução e produção de relações sociais num dado modo de produção, ou a maneira de agir e de pensar que o indivíduo encontra preestabelecida. Para esses autores, "instituição" é um reflexo da forma como as relações de produção se organizam e essa herança social é um dos efeitos da luta de classes.

Esses mesmos autores contabilizam dois significados para a noção de organização: a) para designar conjuntos práticos que perseguem objetivos como a produção ou distribuição de bens e serviços, a formação de homens ou a gestão dos seus lazeres, portanto, significados atribuídos a "realidades sociais" (Lapassade, 1989) e b) para designar certas condutas ou processos sociais, como a mobilização dos meios para atingir os objetivos coletivos (produzir, educar, distribuir), ou o ato de organizar.

Os analistas institucionais identificam, sob um enfoque teórico de assumida inspiração hegeliana, três momentos do conceito de instituição: o momento da 
universalidade, tendo por conteúdo os sistemas de normas, os valores que orientam a socialização, a ideologia, enfim, o instituído; o momento da particularidade, onde o seu conteúdo se resume às determinações materiais $e$ sociais que negam a universalidade dada no primeiro, sendo o momento instituinte; o momento de singularidade, onde o conceito de instituição tem por conteúdo as formas organizacionais, jurídicas ou anônimas necessárias para atingir determinado objetivo ou determinada finalidade, o momento, por fim, da institucionalização. Dialeticamente, um momento está contido no anterior e o nega na ação concreta dos indivíduos e das coletividades (Lourau, 1996). O movimento institucionalista nega a oposição entre o particular e o geral que oblitera o terceiro momento do conceito de instituição e, sobretudo, a ação recíproca dos três momentos. Ainda segundo Lourau, nesse mesmo texto, com essa oposição produzem-se antinomias que só poderiam ser resolvidas pela preponderância dada à sociedade - estrutura, ou ao indivíduo - ação.

Lourau (2001, p.130) demarca as diferenças da noção de instituição desta corrente com o estrutural-funcionalismo:

a la institución durkheimiana parsoniana que designa una estructura estática de normas y de funciones, estructura exterior a nosotros - indivíduos y grupos nuestro paradigma opone el modelo dinámico de la institucionalización y de la implicación dentro de la institucionalización.

A análise institucional critica os autores da sociologia das organizações por autonomizarem o terceiro momento do conceito de instituição, o momento da singularidade ou da institucionalização, dando ênfase à racionalidade e positividade das formas sociais em detrimento da história, das contradições e da luta de classes. A teoria das organizações, na concepção desses analistas institucionais, não está atenta para a relação dialética de negação e positivação de um momento pelo outro. Ela cristaliza a institucionalização, não vendo que "os conjuntos práticos não são totalidades fechadas e acabadas em si mesmas, $e$ sim que o seu sentido é sempre externo a ela, na história, no modo de produção e na formação social em que está constituída" (Lourau \& Lapassade, 1972, p.120).

Os socioanalistas contribuíram de forma substancial para o desenvolvimento da análise institucional, aplicando-a à prática social dos grupos e das organizações, $e$ professando o poder instituinte desses grupos em uma organização social e seu potencial de transformação questionando, assim, a pretensa estabilidade das organizações. A análise institucional em situação de intervenção ou socioanálise dá, portanto, um passo adiante na análise das organizações, avançando do paradigma grupal predominante entre os psicossociólogos para o paradigma institucional.

\section{Os campos de intervenções organizacionais: o esquema analítico proposto}

Foi mediante a leitura dos três blocos de abordagens, apresentadas de forma bem sucinta, que construímos um esquema analítico composto pelo que estamos designando como "campos metodológicos de intervenção organizacional". A escolha das três abordagens, conquanto seja bastante arbitrária e restrita, tendo 
em vista a complexidade do debate que se trava no campo das ciências humanas, foi uma tentativa de destacar, com base em alguns autores, a importância da compreensão da relação entre estrutura $e$ ação, determinação $e$ liberdade, reprodução e mudança, pares de opostos, digamos assim, fundamentais para a compreensão das organizações.

Nossa intenção, ao construir tal esquema, foi a de realizar uma leitura crítica da produção teórica recente do campo da gestão e avaliação em saúde, visando reconhecer os referenciais adotados por seus autores, conforme defendido por Lins (2004) e como será apresentado em artigos futuros. Defendemos a idéia de que, para além da análise das produções teóricas, o esquema analítico poderia, com pequenas modificações, ser utilizado para interrogar as propostas metodológicas de intervenção nas organizações, sejam elas restritas ao campo da avaliação, sejam, de forma mais ampla, como instrumento de gestão. Isto porque as intervenções se baseiam sempre, como já destacamos antes, em algum referencial teórico, mais ou menos explícito.

A noção de "campos metodológicos de intervenção organizacional", que compõe o quadro analítico que estamos utilizando, é inspirada na noção homônima de Pierre Bourdieu (1983), com o significado a ele atribuído como diferenciação das esferas sociais, como especialistas: i) criados ou impulsionados por indivíduos particularmente importantes, estabelecendo novos conteúdos e relações de poder; ii) atores com posições definidas por maior ou menor poder por eles detidos, e legitimidade, posturas, comportamentos, valores; iii) campos de poder e de conhecimento.

Essa denominação não é casual, uma vez que acreditamos serem as propostas de intervenção organizacional, como já explicitamos, devedoras de concepções teóricas mais ou menos hegemônicas entre os analistas organizacionais. Devedoras, portanto, de atores individuais ou grupos com maior acúmulo de recursos para implementar suas concepções de mundo e suas maneiras de influenciar a dinâmica social.

Esses campos representam um esforço de construir categorias analíticas com base nos conceitos presentes nas abordagens ou linhas de pensamento anteriormente comentadas (a teoria da estruturação de Anthony Giddens e o estruturacionismo de Bourdieu; a fenomenologia sociológica de Alfred Schutz, Peter Berger e Thomas Luckmann; a teoria estrutural-funcionalista de Talcott Parsons, $e$ os analistas institucionais, mais especificamente Lourau e Lapassade).

Partimos das categorias elaboradas pela socioanálise quando da definição dos três momentos do conceito de instituição (o universal, o particular e o singular), para definir três tipos ideais de campos de intervenções, como se apresentam a seguir:

1 Campo metodológico de intervenções universalistas (CMIU). As intervenções propostas nesse campo representariam a "conserva" ou a predominância da "memória" na prática dos atores. A ação/liberdade dos sujeitos estaria determinada por um eixo racional/legal, pela estrutura, ordem e regras. Considerando o eixo racional/legal como transmissor de normas, legislações e objetivos oficiais. O projeto de indivíduos e/ou grupos seria a pura identificação com os objetivos organizacionais: nos discursos não se identificariam desvios do eixo estruturante, ou outros projetos. Nesse tipo, não se consideram equipes compostas por sujeitos criativos e desejantes. Criatividade e desejo se dão no 
mesmo sentido do eixo estruturante, sendo por ele capturados. Portanto, a estrutura determinaria a ação $e$ a criatividade dos atores. As equipes de profissionais, seus conhecimentos e suas habilidades seriam vistos como "recursos humanos" ou "insumos" necessários ao alcance do projeto. A presença da disciplina e do controle é o eixo central dos métodos de gestão. A organização é vista como um organismo/sistema que tende à homeostase. Nela, há a introjeção das normas, fundamentada na busca por consenso e cooperação, onde os dissensos e conflitos tendem a ser resolvidos de forma gradual e sistemática. Não há, na prática, interesses divergentes, pois os interesses da sociedade, assim como as normas, são ou devem ser introjetados pelos indivíduos. A concepção de governabilidade é normativa: a norma apresenta-se inerente ao sujeito, que considera sua governabilidade em termos do que ela o capacita a fazer e dos limites impostos à ação/criatividade dos demais. Há uma fixação no momento da universalidade, da unidade positiva ou do instituído. Este seria o campo típico de intervenção dos autores que aderem implícita ou explicitamente às concepções $e$ princípios do estrutural-funcionalismo de Talcott Parsons e da clássica Administração Científica de Taylor e Fayol e dos seus seguidores.

2 Campo metodológico de intervenções particularistas (CMIP). A ação/liberdade dos sujeitos pode definir e redefinir a estrutura da organização. Essa linha de intervenção vê a ação humana, portanto, a liberdade, como fator preponderante para as mudanças, onde as organizações são estruturadas por eixos baseados nos interesses de pequenos grupos e a criatividade/necessidade dos atores é definida/partilhada dentro desse grupo, pois partilham a mesma visão de mundo. A capacidade de governo está representada nas capacidades humanas $e$ implementá-las faz parte da estratégia do dirigente, pois potencializa sua governabilidade. Há uma negação da unidade positiva e uma supervalorização dos movimentos instituintes e da subjetividade. A ênfase é nas particularidades, primeira negação do momento universal. Cada indivíduo constrói o seu próprio mundo, portanto, os projetos são individuais - compartilhados pelo grupo. Porém, como necessita de estoques de conhecimentos e de materiais e métodos que são oferecidos por outros, a capacidade de permanência e expansão do grupo é vista como a possibilidade de acúmulo de recursos pelo ator ou grupo. A ênfase da gestão se dá pela tentativa de atender aos interesses de grupos com maior capacidade de mobilizar recursos em prol dos seus interesses. A este campo se vinculam os projetos metodológicos próximos à fenomenologia sociológica ou sociologia compreensiva.

3 Campo metodológico de intervenções singulares (CMIS). Este campo de intervenções metodológicas deixa transparecer a busca da síntese dialética entre estrutura e ação, entre memória e criatividade, entre norma e liberdade, entre objetivismo e subjetivismo e entre instituído e instituinte. Essas práticas reconhecem, efetivamente, a existência de diversos segmentos dentro das organizações. Segmentos esses atravessados por sentimentos de pertencimentos que desfazem as duplas dicotômicas entre explorados/exploradores; que exercem ações, ao mesmo tempo, transformativas e cristalizantes, em contextos (estruturas) capacitadores e condicionantes de sua ação, já que lhes fornece recursos e regras.

O projeto oficial da organização concretiza o discurso da instituição à qual se vincula, representando o grande eixo normalizador, atravessado, porém, ou 
"transversalizado" por diversos outros projetos disputados por grupos protagonistas que demonstram habilidades na manipulação de recursos em prol de sua autonomia. Para este campo, pensamos tenderem as propostas metodológicas mais vinculadas ao materialismo histórico e autores que buscaram sínteses entre as diversas escolas sociológicas, como os estruturacionistas e os analistas institucionais franceses aqui apresentados.

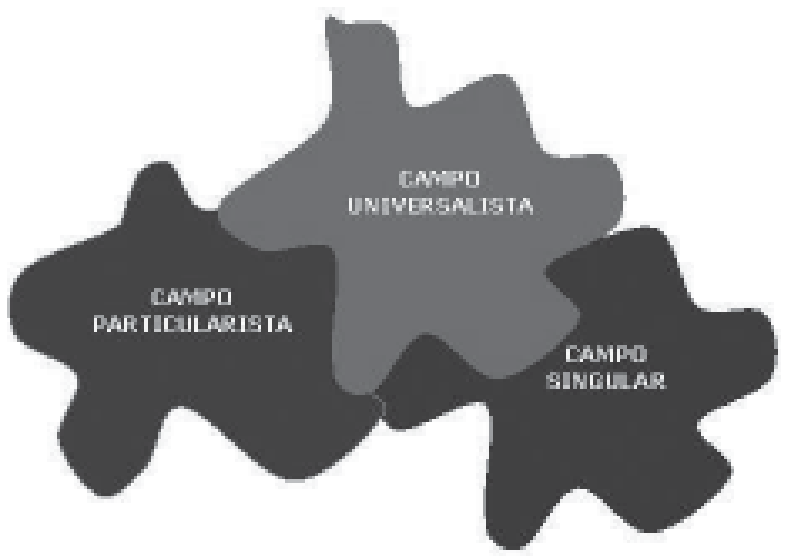

Figura 1. Campos metodológicos de intervenção organizacional

Nosso quadro analítico é composto, portanto, por esses três campos, representados na figura 1 . Os campos, representados por áreas de diferentes tonalidades, representariam produções mais ou menos típicas, indo até os limites dos demais campos. Naturalmente, como são tipos ideais, não se pretende o recorte das diversas propostas de intervenção para enquadrá-las completamente em um dos tipos formulados. Esta morfologia - de certa forma amebiana, onde as continuidades de um campo se imiscuem sobre as áreas de outro campo - quer demonstrar as interpenetrações que se esperam encontrar nas várias metodologias de intervenção organizacional. Pensando nos prolongamentos de um campo sobre ou sob o outro, pretende-se apenas indicar alguns pertencimentos que estarão atravessados por inúmeros outros. Os campos, como matrizes, estariam, portanto, detectando tendências teórico-metodológicas.

Acreditamos que um uso secundário desse esquema analítico poderia ser a identificação de centros universitários, possivelmente aqueles cujas produções teóricas e estudos se aproximam mais do "núcleo central" de um dos campos, e que representariam centros de produções teórico-metodológicas de onde emanariam influências para outros grupos.

\section{Conclusão}

O esquema analítico proposto, construído com base no que estamos denominando de "campos metodológicos de intervenção organizacional", foi utilizado para a leitura e discussão de teses de doutorado defendidas na área de gestão e avaliação 
em saúde, produzidas em alguns centros de pesquisa brasileiros, de 2000 a 2004 (Lins, 2004). A experiência dos autores deste artigo, na área de gestão e avaliação de serviços de saúde, Ihes havia permitido tomar, como pressuposto inicial do trabalho, a idéia de que grande parte da produção teórica acadêmica nessa área estivesse presa ao referencial estrutural-funcionalista. O esquema analítico possibilitou a identificação de trabalhos ainda aprisionados, pelo menos em parte, ao referencial estrutural-funcionalista, mas também possibilitou a identificação do esforço dos autores contemporâneos na busca por novos paradigmas na aproximação dos objetos de que tratam a gestão e a avaliação em saúde.

A descoberta do esforço de alguns pesquisadores na busca por novos paradigmas que os auxiliassem na compreensão e apreensão dos seus objetos de estudo foi um dos resultados do estudo. Nossa aposta é de que o esquema analítico testado no estudo permita a leitura e análise das proposições de intervenções organizacionais apresentadas a gestores $e$ avaliadores. Espera-se, com a proposição deste esquema analítico, oferecer aos leitores, sejam gestores, avaliadores ou estudiosos das organizações da saúde, um roteiro para a leitura dos diversos programas $e$ projetos formulados, $e$ a identificação da sua adequação à realidade $e$ aos propósitos de transformação de uma situação indesejada, que vemos explicitados como objetivos freqüentes das equipes gestoras das organizações da saúde.

\section{Referências}

AGUILAR, M.J.; ANDER-EGG, E. Avaliação de serviços e programas sociais. 2.ed. Petrópolis: Vozes, 1995.

BERGER, P.; LUCKMANN, T. A construção social da realidade. 11.ed. Petrópolis: Vozes, 1994.

BOUDON, R. (Org.). Tratado de Sociologia. Rio de Janeiro: Jorge Zahar, 1995.

BOURDIEU, P. Esboço de uma teoria prática. In: ORTIZ, R. (Org.). Pierre Bourdieu. São Paulo: Ática, 1983. p.4681 (Grandes Cientistas Sociais 39).

CAMPOS, G.W.S. Subjetividade e administração de pessoal: considerações sobre modos de gerenciar o trabalho em equipes e saúde. In: MERHY, E.E.; ONOCKO, R. (Orgs.). Agir em Saúde. São Paulo: Hucitec, 1997. p.229-66.

Um método para análise e co-gestão de coletivos. São Paulo: Hucitec, 2000.

COHEN, E.; FRANCO, R. Avaliação de projetos sociais. Petrópolis: Vozes, 1994.

COHEN, I.J. Teoria da estruturação e práxis social. In: GIDDENS, A.; TURNER, J. (Orgs.). Teoria social hoje. São Paulo: EDUNESP, 1999. p.393-446.

CURADO, I.B. O que é saber em administração? Uma tipologia dos saberes administrativos. Disponível em: <www.fgvsp.br/iberoamerican/Papers/0295_saber\%20lberoamerica.pdf>. Acesso em: 03 ago.2007.

DOMINGUES, J.M. Teorias sociológicas no século XX. Rio de Janeiro: Civilização Brasileira, 2001a.

A sociologia de Talcott Parsons. Niterói: EDUFF, 2001b.

DONABEDIAN, A. Organização. In: BOUDON. R. (Org.). Tratado de Sociologia. Rio de Janeiro: Zahar, 1995. The quality of care: how can it be assessed? JAMA, v.12, n.260, p.1743-8, 1988.

The methods and fidings of quality assessment and monitoring: an illustrated analisys. Ann Harbor: Health Administration Press, 1985. v.3.

The criteria and standards of quality. Ann Harbor: Health Administration Press, 1982. v.2. 
LINS, A.M.; CECÍLIO, L.C.O.

FRIEDBERG, E. O poder e a regra: dinâmicas da ação organizada. Lisboa: Instituto Piaget, Editions du Seuil, 1993.

GIDDENS, A. Novas regras do método sociológico: uma crítica positiva das sociologias compreensivas. Rio de Janeiro: Zahar, 1978

KUHN, T.S. A estrutura das revoluções científicas. São Paulo: Perspectiva, 1975.

LAPASSADE, G. Grupos, organizações e instituições. 3.ed. Rio de Janeiro: Francisco Alves, 1989.

LAPASSADE, G ; LOURAU, R. Chaves da sociologia. Rio de Janeiro: Civilização Brasileira, 1972.

LINS, A.M. Produções teóricas na área de gestão e avaliação em saúde: o esforço de construção de um novo paradigma. 2004. Tese (Doutorado) - Departamento de Medicina Social e Preventiva, Universidade Estadual de Campinas, Campinas.

LOURAU, R. A análise institucional. Petrópolis: Vozes, 1996.

. Libertad de movimientos: una introducción al análisis institucional. Buenos Aires: Ed. Universitaria de Buenos Aires, 2001.

MINAYO, M.C.S. O desafio do conhecimento: pesquisa qualitativa em saúde. 2.ed. São Paulo/Rio de Janeiro: Hucitec, 1993

ORTIZ, R. Introdução. In: . (Org.). Pierre Bourdieu. São Paulo: Ática, 1983. (Coleção Grandes

Cientistas Sociais, n.39).

PATTON, M.Q. Pratical evaluation. Beverly Hills: Sage Publications, 1982.

QUINTANEIRO, T.; OLIVEIRA, M.G.M. Labirintos simétricos: introdução à teoria sociológica de Talcott Parsons. Belo Horizonte: Ed. UFMG, 2002.

SCHUTZ, A. Fundamentos da fenomenologia. In: WAGNER, H.R. (Org.). Fenomenologia e relações sociais. Rio de Janeiro: Zahar, 1979. p.53-71.

SILVERMAN, D. Teoria de las organizaciones. Buenos Aires: Ediciones Nueva Visión, 1975.

SOUSA, R.S. O funcionalismo sistêmico nas teorias social e organizacional: evolução e crítica. REAd, v.7, n.1, 2002. Disponível em: <http://www.read.adm.ufrgs.br>. Acesso em: 03 ago. 2007.

LINS, A.M.; CECÍLIO, L.C.O. Campos de intervenciones de organización: contribución de las ciencias humanas para una lectura crítica de las propuestas de gestión de las organizaciones de salud. Interface - Comunic., Saúde, Educ., v.11, n.23, p.503-14, set/dez 2007.

El objetivo de este artículo es presentar un esquema analítico, que puedan utilizar los estudiosos de las organizaciones, sobre todo gestores y evaluadores en salud, como guía de una lectura crítica de propuestas de intervenir en la organización que se les presenta cotidianamente y se pretenden transformadoras de una situación indeseada. El esquema presentado es el resultado de una investigación que discutió tesis de doctorado defendidas, entre los ãnos 2000 y 2004 , en las principales universidades brasileñas; tratando de identificar los paradigmas usados en estas obras académicas recientes. Se compone de tipos ideales denominados "campos de intervenciones de organización", construidos con la contribución de algunas producciones teóricas de las ciencias humanas.

PALABRAS CLAVE: Análisis organizacional. Sistema de salud. Gestión en salud. Evaluación en salud. 